\title{
Gene expression profiling analysis of ovarian cancer
}

\author{
JI-GANG YIN，XIAN-YING LIU，BIN WANG，DAN-YANG WANG，MAN WEI，HUA FANG and MEI XIANG
}

Key Lab of Zoonosis Research, Ministry of Education, The Second Hospital of Jilin University, Changchun, Jilin 130041, P.R. China

Received March 8, 2015; Accepted March 18, 2016

DOI: $10.3892 / \mathrm{ol} .2016 .4663$

\begin{abstract}
As a gynecological oncology, ovarian cancer has high incidence and mortality. To study the mechanisms of ovarian cancer, the present study analyzed the GSE37582 microarray. GSE37582 was downloaded from Gene Expression Omnibus and included data from 74 ovarian cancer cases and 47 healthy controls. The differentially-expressed genes (DEGs) were screened using linear models for microarray data package in $\mathrm{R}$ and were further screened for functional annotation. Next, Gene Ontology and pathway enrichment analysis of the DEGs was conducted. The interaction associations of the proteins encoded by the DEGs were searched using the Search Tool for the Retrieval of Interacting Genes, and the protein-protein interaction (PPI) network was visualized by Cytoscape. Moreover, module analysis of the PPI network was performed using the BioNet analysis tool in R. A total of 284 DEGs were screened, consisting of 145 upregulated genes and 139 downregulated genes. In particular, downregulated FBJ murine osteosarcoma viral oncogene homolog (FOS) was an oncogene, while downregulated cyclin-dependent kinase inhibitor 1A (CDKN1A) was a tumor suppressor gene and upregulated cluster of differentiation 44 (CD44) was classed as an 'other' gene. The enriched functions included collagen catabolic process, stress-activated mitogen-activated protein kinases cascade and insulin receptor signaling pathway. Meanwhile, FOS (degree, 15), CD44 (degree, 9), B-cell CLL/lymphoma 2 (BCL2; degree, 7), CDKN1A (degree, 7) and matrix metallopeptidase 3 (MMP3; degree, 6) had higher connectivity degrees in the PPI network for the DEGs. These genes may be involved in ovarian cancer by interacting with other genes in the module of the PPI network (e.g., BCL2-FOS, BCL2-CDKN1A, FOS-CDKN1A, FOS-CD44, MMP3-MMP7 and MMP7-CD44). Overall, BCL2, FOS, CDKN1A, CD44, MMP3 and MMP7 may be correlated with ovarian cancer.
\end{abstract}

Correspondence to: Mrs. Mei Xiang, Key Lab of Zoonosis Research, Ministry of Education, The Second Hospital of Jilin University, 5333 Xian Road, Changchun, Jilin 130041, P.R. China E-mail: sxiaogmei@163.com

Key words: ovarian cancer, differentially-expressed genes, protein-protein interaction network, module analysis

\section{Introduction}

Ovarian cancer is a common malignant tumor of the female reproductive organs, with an incidence ranked third of all malignant tumors, and the majority of these tumors are epitheliomas (1). With not only non-typical early symptoms but also complex ovarian embryonic development, tissue dissection and endocrine functions, only $19 \%$ of all ovarian cancers can be diagnosed at an early stage, and the mortality rate for this disease is highest in the field of gynecological oncology (2).

In recent years, a number of studies have been performed to investigate the molecular mechanisms of ovarian cancer. For example, as a member of the protein kinase B family, v-akt murine thymoma viral oncogene homolog 2 (AKT2) can be frequently activated and induce the apoptosis of human primary ovarian cancer by inhibiting the phosphoinositide 3-kinase (PI3K)/Akt pathway (3). With elevated expression levels in patients with epithelial ovarian cancer, ovarian cancer carbohydrate antigen 125 can be used for monitoring patients with ovarian cancer (4). As a chemokine receptor, chemokine (C-X-C motif) receptor 4 can be expressed on a subset of ovarian cancer cells and may have important roles in the development of site-specific metastasis $(5,6)$. Chemokine (C-X-C motif) ligand 12 may affect ovarian cancer through several methods, such as stimulating cell migration and invasion, inducing establishment of a cytokine network and DNA synthesis in conditions that are suboptimal for tumor cell growth (7). PI3Ks are lipid kinases associated with neoplasia (8), and phosphoinositide-3-kinase, catalytic subunit $\alpha$ (which encodes the p110alpha catalytic subunit of PI3-kinase) is an oncogene that plays a critical role in ovarian cancer (9).

In 2012, Zhao et al (10) used a whole-genome microarray approach to analyze genes that differed between ovarian cancer cases and healthy controls, and obtained a total of 10,435 mRNA genes that could be used for downstream analysis. Using the data obtained by Zhao et al (10), the present study aimed to obtain the differentially-expressed genes (DEGs) and investigate their possible functions by Gene Ontology (GO) and pathway enrichment analyses. In addition, the interaction associations between these DEGs were searched using the protein-protein interaction (PPI) network and modules of the PPI network.

\section{Materials and methods}

Microarray data. The expression profile of GSE37582, deposited by Zhao et al (10), was downloaded from Gene Expression 
Omnibus (http://www.ncbi.nlm.nih.gov/geo/) and was based on the platform of the GPL6947 Illumina HumanHT-12 V3.0 expression beadchip. GSE37582 included data from 74 ovarian cancer cases and 47 healthy controls.

DEG screening and functional annotation. Once GSE37582 had been downloaded, microarray data was preprocessed by robust multi-array average (11) background correction. Next, quantile normalization was conducted. The average value of multiple probes mapped with one gene was obtained as the ultimate gene expression value. The linear models for microarray data package in $\mathrm{R}(12)$ was used to analyze the DEGs between ovarian cancer cases and healthy controls. A false discovery rate (FDR) of $<0.05$ and $\operatorname{llog}_{2}$ fold-changel $>1$ were used as the cut-off criteria.

To predict genes with functions of transcription factors, the DEGs were screened in combination with the transcription factors database. In combination with the tumor suppressor gene (TSG) (13) and tumor-associated gene (14) databases, the TSGs and oncogenes were then further screened from the DEGs.

Functional and pathway enrichment analysis. Through use of controlled and structured vocabularies, $\mathrm{GO}$ (www.geneontology. org/) can act as a community-based bioinformatics resource and classify gene product functions (15). As an integrated database resource, the Kyoto Encyclopedia of Genes and Genomes (KEGG; www.genome.jp/kegg/) consists of systems information, genomic information and chemical information (16). GO and KEGG pathway enrichment analyses were performed for the DEGs. $\mathrm{P}<0.05$ was used as the cut-off criterion.

PPI network and module construction. The Search Tool for the Retrieval of Interacting Genes online software (17) was used to search interaction associations of the proteins encoded by the DEGs, and the required confidence (combined score) of $>0.4$ was used as the cut-off criterion. Cytoscape (18) was used to visualize the PPI network. Next, connectivity degree analysis was conducted and key nodes (i.e., hub proteins) (19) were searched. The proteins in the network were defined as the nodes. Next, the BioNet (20) analysis tool in R was used to screen modules of the PPI network. The FDR was set to 3.

\section{Results}

DEG analysis and functional annotation. A total of 284 DEGs were screened, consisting of 145 upregulated genes and 139 downregulated genes. Only 1 transcription factor was significantly upregulated, while 8 transcription factors were significantly downregulated. For the upregulated genes, there was 1 oncogene, 4 TSGs and 3 'other' genes [the influence of 'other' genes on tumors was unclear, and could therefore not be distinguished as oncogenes or tumor suppressor genes, including cluster of differentiation 44 (CD44)]. For the downregulated genes, there were 4 oncogenes [such as FBJ murine osteosarcoma viral oncogene homolog (FOS)], 11 TSGs [such as cyclin-dependent kinase inhibitor 1A (CDKN1A)] and 5 'other' genes (Table I).

Functional and pathway enrichment analysis. The enriched GO functions for the DEGs are listed in Table II. For the upregulated genes, the enriched GO functions included the collagen catabolic process $\left(\mathrm{P}=1.86 \times 10^{-2}\right)$, extracellular matrix disassembly $\left(\mathrm{P}=4.50 \times 10^{-3}\right)$ and negative regulation of intrinsic apoptotic signaling pathway in response to DNA damage by p53 class mediator $\left(\mathrm{P}=3.07 \times 10^{-3}\right)$. For the downregulated genes, the enriched GO functions included the negative regulation of cell growth $\left(\mathrm{P}=1.39 \times 10^{-4}\right)$, stress-activated mitogen-activated protein kinases (MAPK) cascade $\left(\mathrm{P}=1.73 \times 10^{-3}\right)$ and insulin receptor signaling pathway $\left(\mathrm{P}=1.19 \times 10^{-2}\right)$.

The enriched KEGG pathways for the DEGs are listed in Table III. For the upregulated genes, the enriched KEGG pathways included the pentose phosphate pathway $\left(\mathrm{P}=2.43 \times 10^{-2}\right)$, hematopoietic cell lineage $\left(\mathrm{P}=4.46 \times 10^{-2}\right)$ and rheumatoid arthritis $\left(\mathrm{P}=4.84 \times 10^{-2}\right)$. Meanwhile, for the downregulated genes, the enriched KEGG pathways included the MAPK signaling pathway $\left(\mathrm{P}=3.77 \times 10^{-6}\right)$, pathways in cancer $\left(\mathrm{P}=7.47 \times 10^{-3}\right)$ and toxoplasmosis $\left(\mathrm{P}=7.24 \times 10^{-5}\right)$.

PPI network and module construction. The PPI network consisted of 110 nodes and 136 interactions. There were 45 upregulated genes and 65 downregulated genes in the PPI network of the DEGs (Fig. 1). The number of upregulated genes was less than that of the downregulated genes. The DEGs, which encoded proteins with connectivity degrees of $\geq 5$, included FOS (degree, 15), CD44 (degree, 9), B-cell CLL/lymphoma 2 (BCL-2; degree, 7), CDKN1A (degree, 7), DnaJ heat shock protein family (Hsp40) member B1 (degree, 7), AKT2 (degree, 7) and matrix metalloproteinase 3 (MMP3; degree, 6).

A module was obtained from the PPI network of the DEGs (Fig. 2). The module had 62 nodes and 93 interactions. In this module, the number of upregulated genes was less than the number of downregulated genes. Moreover, BCL2 could interact with FOS and CDKN1A, FOS could interact with CDKN1A and CD44, and MMP7 could interact with MMP3 and CD44. The enriched GO functions for the DEGs in the module included extracellular matrix organization $\left(\mathrm{P}=2.86 \times 10^{-6}\right)$, response to drug $\left(\mathrm{P}=3.36 \times 10^{-4}\right)$ and regulation of cell motility $\left(\mathrm{P}=1.37 \times 10^{-3}\right)$ (Table IV). The enriched KEGG pathways for the DEGs in the module are listed in Table $\mathrm{V}$, including pathways in cancer $\left(\mathrm{P}=9.01 \times 10^{-5}\right)$, prostate cancer $\left(\mathrm{P}=3.98 \times 10^{-5}\right)$, colorectal cancer $\left(\mathrm{P}=7.89 \times 10^{-5}\right)$ and acute myeloid leukemia $\left(\mathrm{P}=7.44 \times 10^{-4}\right)$.

\section{Discussion}

In the present study, a total of 284 DEGs were screened, consisting of 145 upregulated genes and 139 downregulated genes. In particular, downregulated FOS was an oncogene, while downregulated CDKN1A was a tumor suppressor gene and upregulated CD44 was classed as an 'other' gene. The enriched functions included the collagen catabolic process, stress-activated MAPK cascade and insulin receptor signaling pathway. Meanwhile, FOS (degree, 15), CD44 (degree, 9), BCL2 (degree, 7), CDKN1A (degree, 7) and MMP3 (degree, 6) had higher connectivity degrees in the PPI network for the DEGs. Also, a module was obtained from the PPI network of the DEGs.

Bcl-2 belongs to an family of pro- and antiapoptotic proteins (21), able to enhance cell survival by inhibiting 
Table I. Functional annotations of the differentially-expressed genes.

\begin{tabular}{|c|c|c|c|c|}
\hline Regulation & TF numbers & TF symbols & TAG numbers & TAG symbols \\
\hline Up & 1 & KLF12 & 8 & $\begin{array}{l}\text { TCL1B, CTNND1, MUC1, PTPRF, STARD13, } \\
\text { CD44, FES, MIAT }\end{array}$ \\
\hline Down & 8 & $\begin{array}{l}\text { ASCL1, ETV4, HSF1, } \\
\text { LMO3, PML, RUNX3, } \\
\text { TCF7, USF2 }\end{array}$ & 20 & $\begin{array}{l}\text { AKT2, FOS, GNA12, PVT1, CD82, CDKN1A, } \\
\text { FBXO32, GADD45G, MAL, PML, PPP1R3C, } \\
\text { RUNX3, SCGB3A1, SOCS1, VHL, ASCL1, } \\
\text { BCAS1, OGG1, PMS2, RHOB }\end{array}$ \\
\hline
\end{tabular}

TF, transcription factor; TAG, tumor-associated gene.

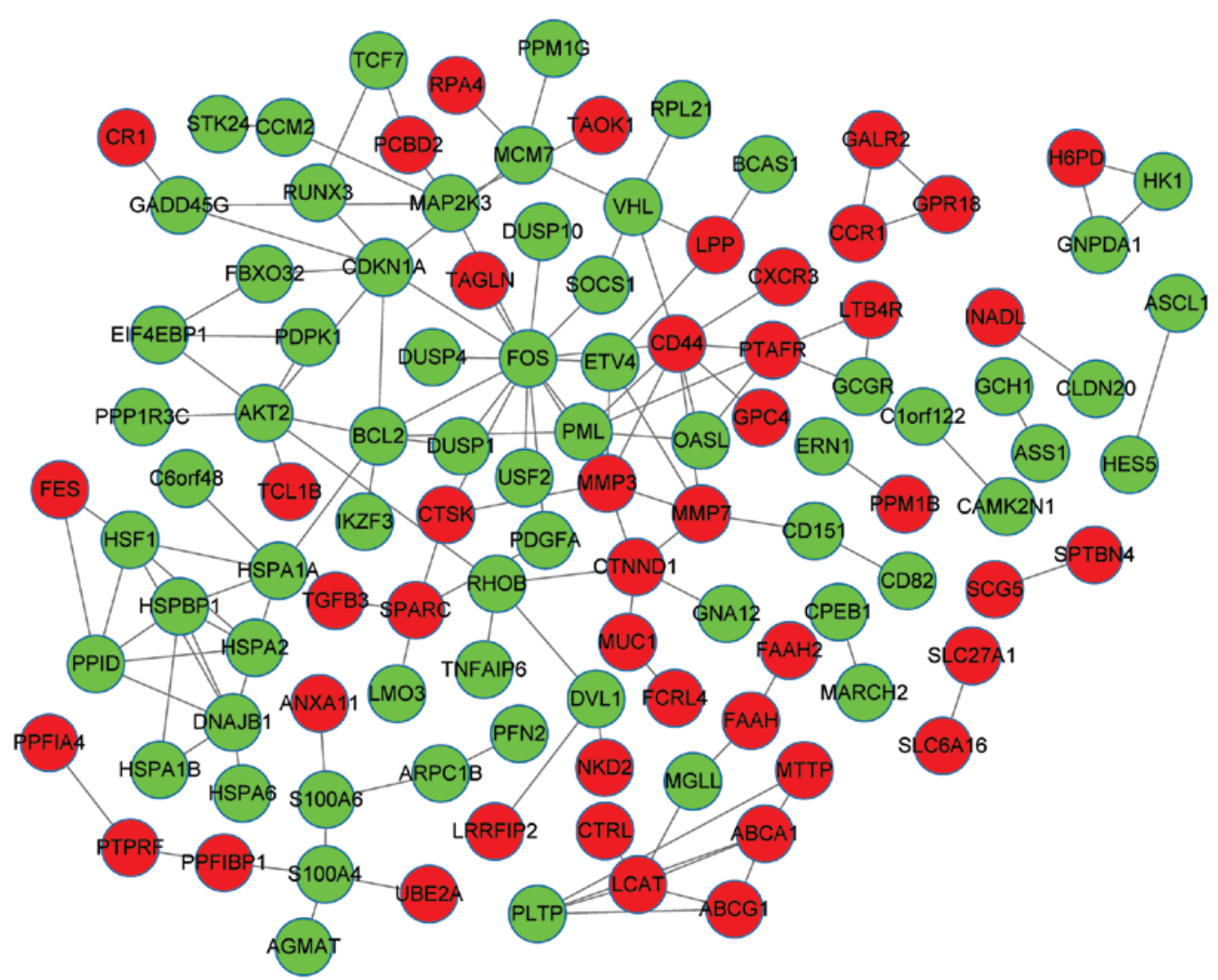

Figure 1. Protein-protein interaction network of the differentially-expressed genes. Red and green circles represent the up- and downregulated genes, respectively.

apoptosis (22). BCL2 is frequently expressed in primary ovarian carcinoma and may be an important determinant of drug-induced apoptosis in ovarian cancer $(23,24)$. By deregulating programmed cell death and changing sensitivity to chemotherapy, alteration of the Bax/Bcl-2 balance may affect the clinical course of ovarian cancer (25). As a member of the Bcl-2 family, ABT-737 can significantly improve the activity of carboplatin and thus may be of great use in the treatment of patients with ovarian cancer (26). These data may indicate that the expression level of BCL2 is associated with ovarian cancer. The c-fos protein may act as a tumor suppressor and may be involved in apoptosis (27). Expression of Fos can affect the progression of ovarian carcinoma and may function as a prognostic factor (28). Thus, we speculated that FOS may play a role in ovarian cancer. In the module, the present study found that BCL2 exhibited interaction associations with FOS, indicating that BCL2 may also play a role in ovarian cancer by mediating FOS.

As one of the most important CDK inhibitors, p27Kip1 can function in the $\mathrm{G}_{1}$ cell cycle arrest induced by anti-human epidermal growth factor receptor type 2 antibody and inhibit tumor growth through post-translational regulation (29). As the product of the CDKN2A gene at chromosome 9p2, the CDK inhibitor p16 is associated with the progression and unfavorable prognosis of ovarian cancer $(30,31)$. p21, also known as CDKN1A, regulates several processes, including cell growth (32), differentiation (33) and apoptosis (34). Overexpressed CDK inhibitor p21 can reduce the phosphorylation 


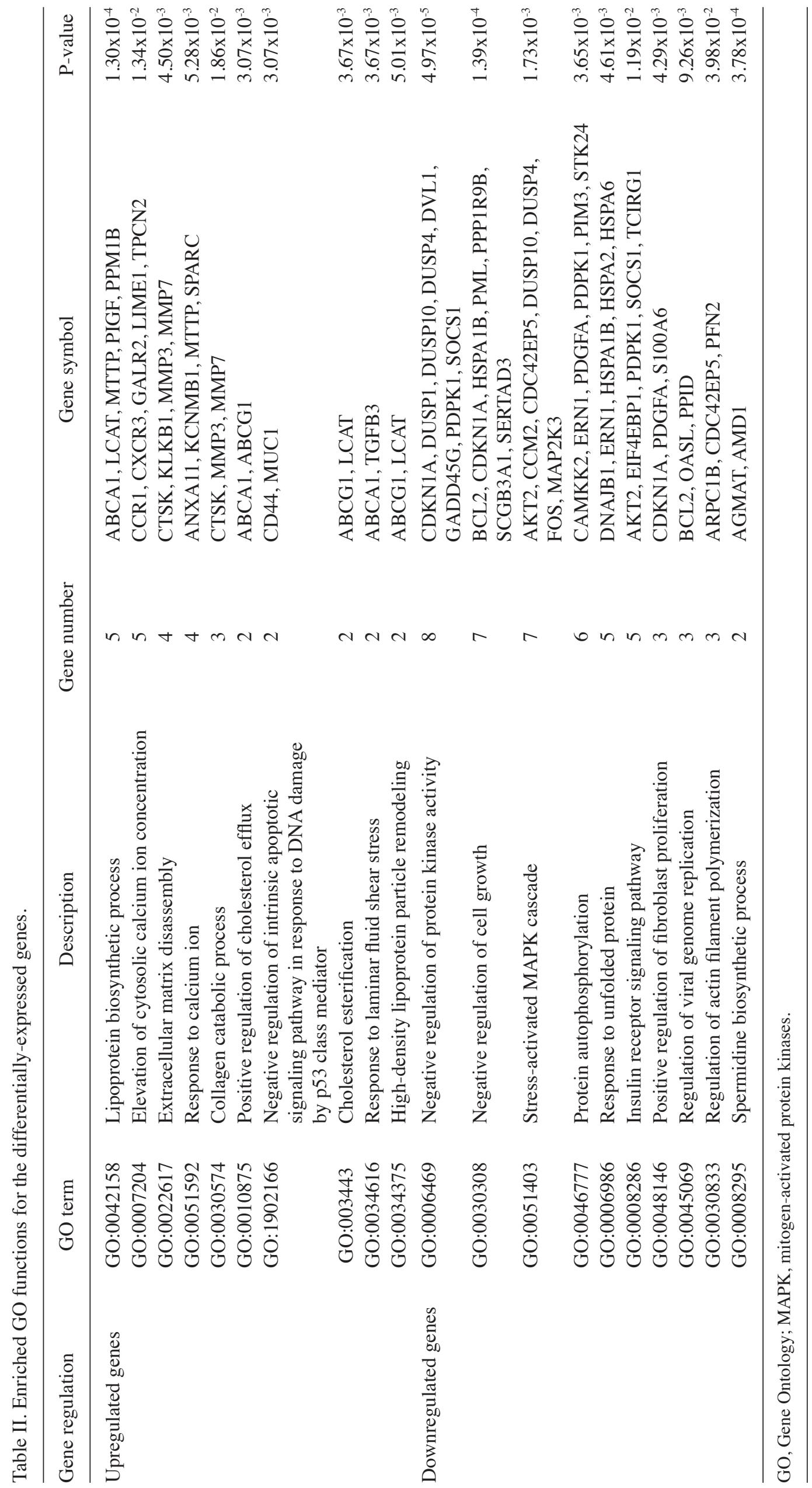


Table III. Enriched KEGG pathways for the differentially-expressed genes.

\begin{tabular}{|c|c|c|c|c|c|}
\hline Gene regulation & Term & Description & $\begin{array}{l}\text { Gene } \\
\text { number }\end{array}$ & Gene symbol & P-value \\
\hline \multirow[t]{3}{*}{ Upregulated genes } & 30 & Pentose phosphate pathway & 2 & H6PD, RBKS & $2.43 \times 10^{-2}$ \\
\hline & 4640 & Hematopoietic cell lineage & 3 & CD1C, CD44, CR1 & $4.46 \times 10^{-2}$ \\
\hline & 5323 & Rheumatoid arthritis & 3 & CTSK, MMP3, TGFB3 & $4.84 \times 10^{-2}$ \\
\hline \multirow[t]{10}{*}{ Downregulated genes } & 4010 & MAPK signaling pathway & 13 & $\begin{array}{l}\text { AKT2, DUSP1, DUSP10, DUSP4, } \\
\text { FOS, GADD45G, GNA12, } \\
\text { HSPA1A, HSPA1B, HSPA2, } \\
\text { HSPA6, MAP2K3, PDGFA }\end{array}$ & $3.77 \times 10^{-6}$ \\
\hline & 5200 & Pathways in cancer & 9 & $\begin{array}{l}\text { AKT2, BCL2, CDKN1A, DVL1, } \\
\text { FOS, PDGFA, PML, TCF7, VHL }\end{array}$ & $7.47 \times 10^{-3}$ \\
\hline & 5145 & Toxoplasmosis & 8 & $\begin{array}{l}\text { AKT2, BCL2, HSPA1A, HSPA1B, } \\
\text { HSPA2, HSPA6, MAP2K3, SOCS1 }\end{array}$ & $7.24 \times 10^{-5}$ \\
\hline & 4141 & $\begin{array}{l}\text { Protein processing in } \\
\text { endoplasmic reticulum }\end{array}$ & 8 & $\begin{array}{l}\text { BCL2, DNAJB1, ERN1, HSPA1A, } \\
\text { HSPA1B, HSPA2, HSPA6, HSPBP1 }\end{array}$ & $3.41 \times 10^{-4}$ \\
\hline & 5215 & Prostate cancer & 6 & $\begin{array}{l}\text { AKT2, BCL2, CDKN1A, PDGFA, } \\
\text { PDPK1, TCF7 }\end{array}$ & $3.48 \times 10^{-4}$ \\
\hline & 4910 & Insulin signaling pathway & 6 & $\begin{array}{l}\text { AKT2, EIF4EBP1, HK1, PDPK1, } \\
\text { PPP1R3C, SOCS1 }\end{array}$ & $3.42 \times 10^{-3}$ \\
\hline & 4144 & Endocytosis & 6 & $\begin{array}{l}\text { CHMP6, HSPA1 A, HSPA1B, } \\
\text { HSPA2, HSPA6, PML }\end{array}$ & $2.01 \times 10^{-2}$ \\
\hline & 3040 & Spliceosome & 5 & $\begin{array}{l}\text { HSPA1A, HSPA1B, HSPA2, } \\
\text { HSPA6, PRPF6 }\end{array}$ & $1.13 \times 10^{-2}$ \\
\hline & 5221 & Acute myeloid leukemia & 4 & AKT2, EIF4EBP1, PML, TCF7 & $3.11 \times 10^{-3}$ \\
\hline & 5210 & Colorectal cancer & 4 & AKT2, BCL2, FOS, TCF7 & $4.22 \times 10^{-3}$ \\
\hline
\end{tabular}

KEGG, Kyoto Encyclopedia of Genes and Genomes; MAPK, mitogen-activated protein kinases.

Table IV. Top 10 enriched GO functions for the differentially-expressed genes in the module.

\begin{tabular}{|c|c|c|c|c|}
\hline GO term & Description & $\begin{array}{l}\text { Gene } \\
\text { number }\end{array}$ & Gene symbol & P-value \\
\hline GO:0030198 & Extracellular matrix organization & 9 & $\begin{array}{l}\text { CTSK, MMP3, CD44, CD151, SPARC, PDGFA, } \\
\text { MMP7, VHL, TGFB3 }\end{array}$ & $2.86 \times 10^{-6}$ \\
\hline GO:0006954 & Inflammatory response & 9 & $\begin{array}{l}\text { LTB4R, CD44, MAP2K3, FOS, CR1, DUSP10, } \\
\text { PTAFR, CXCR3, TNFAIP6 }\end{array}$ & $1.41 \times 10^{-4}$ \\
\hline GO:0022612 & Gland morphogenesis & 7 & $\begin{array}{l}\text { BCL2, CD44, CTNND1, ETV4, PML, PDGFA, } \\
\text { TGFB3 }\end{array}$ & $2.37 \times 10^{-7}$ \\
\hline GO:0006469 & $\begin{array}{l}\text { Negative regulation of protein } \\
\text { kinase activity }\end{array}$ & 7 & $\begin{array}{l}\text { DVL1, CDKN1A, GADD45G, SOCS1, DUSP10, } \\
\text { DUSP1, PDPK1 }\end{array}$ & $2.82 \times 10^{-6}$ \\
\hline GO:0042493 & Response to drug & 7 & $\begin{array}{l}\text { BCL2, CDKN1A, MCM7, FOS, PDGFA, MMP7, } \\
\text { GNA12 }\end{array}$ & $3.36 \times 10^{-4}$ \\
\hline GO:2000145 & Regulation of cell motility & 7 & $\begin{array}{l}\text { BCL2, MMP3, FES, AKT2, PDGFA, CXCR3, } \\
\text { PDPK1 }\end{array}$ & $1.37 \times 10^{-3}$ \\
\hline GO:0043583 & Ear development & 6 & BCL2, DVL1, CCM2, SPARC, PDGFA, TGFB3 & $9.35 \times 10^{-5}$ \\
\hline GO:0051403 & Stress-activated MAPK cascade & 6 & MAP2K3, AKT2, FOS, CCM2, DUSP10, TAOK1 & $1.69 \times 10^{-4}$ \\
\hline GO:0043068 & $\begin{array}{l}\text { Positive regulation of } \\
\text { programmed cell death }\end{array}$ & 6 & CDKN1A, PML, RHOB, DUSP1, PPID, TGFB3 & $1.71 \times 10^{-3}$ \\
\hline GO:0060333 & $\begin{array}{l}\text { Interferon- } \gamma \text {-mediated signaling } \\
\text { pathway }\end{array}$ & 5 & CD44, OASL, SOCS1, PML, PTAFR & $9.81 \times 10^{-6}$ \\
\hline
\end{tabular}


Table V. Enriched KEGG pathways for the differentially-expressed genes in the module.

\begin{tabular}{|c|c|c|c|c|}
\hline Term & Description & $\begin{array}{l}\text { Gene } \\
\text { number }\end{array}$ & Gene symbol & P-value \\
\hline 4010 & MAPK signaling pathway & 14 & $\begin{array}{l}\text { GADD45G, MAP2K3, HSPA2, AKT2, HSPA1A, } \\
\text { FOS, HSPA1B, PDGFA, DUSP10, DUSP1, } \\
\text { GNA12, TAOK1, HSPA6, TGFB3 }\end{array}$ & $2.91 \times 10^{-9}$ \\
\hline 5200 & Pathways in cancer & 10 & $\begin{array}{l}\text { BCL2, DVL1, CDKN1A, AKT2, FOS, PML, } \\
\text { PDGFA, VHL, TCF7, TGFB3 }\end{array}$ & $9.01 \times 10^{-5}$ \\
\hline 5145 & Toxoplasmosis & 9 & $\begin{array}{l}\text { BCL2, MAP2K3, HSPA2, AKT2, HSPA1A, } \\
\text { SOCS1, HSPA1B, HSPA6, TGFB3 }\end{array}$ & $3.30 \times 10^{-7}$ \\
\hline 4141 & $\begin{array}{l}\text { Protein processing in } \\
\text { endoplasmic reticulum }\end{array}$ & 7 & $\begin{array}{l}\text { BCL2, DNAJB1, HSPA2, HSPA1A, HSPA1B, } \\
\text { HSPBP1, HSPA } 6\end{array}$ & $1.68 \times 10^{-4}$ \\
\hline 5215 & Prostate cancer & 6 & BCL2, CDKN1A, AKT2, PDGFA, TCF7, PDPK1 & $3.98 \times 10^{-5}$ \\
\hline 4144 & Endocytosis & 6 & HSPA2, HSPA1A, HSPA1B, PML, HSPA6, TGFB3 & $3.17 \times 10^{-3}$ \\
\hline 5210 & Colorectal cancer & 5 & BCL2, AKT2, FOS, TCF7, TGFB3 & $7.89 \times 10^{-5}$ \\
\hline 4910 & Insulin signaling pathway & 5 & AKT2, SOCS1, EIF4EBP1, PPP1R3C, PDPK1 & $3.14 \times 10^{-3}$ \\
\hline 5221 & Acute myeloid leukemia & 4 & AKT2, PML, EIF4EBP1, TCF7 & $7.44 \times 10^{-4}$ \\
\hline 4612 & $\begin{array}{l}\text { Antigen processing and } \\
\text { presentation }\end{array}$ & 4 & HSPA2, HSPA1A, HSPA1B, HSPA6 & $2.18 \times 10^{-3}$ \\
\hline
\end{tabular}

KEGG, Kyoto Encyclopedia of Genes and Genomes; MAPK, mitogen-activated protein kinases.

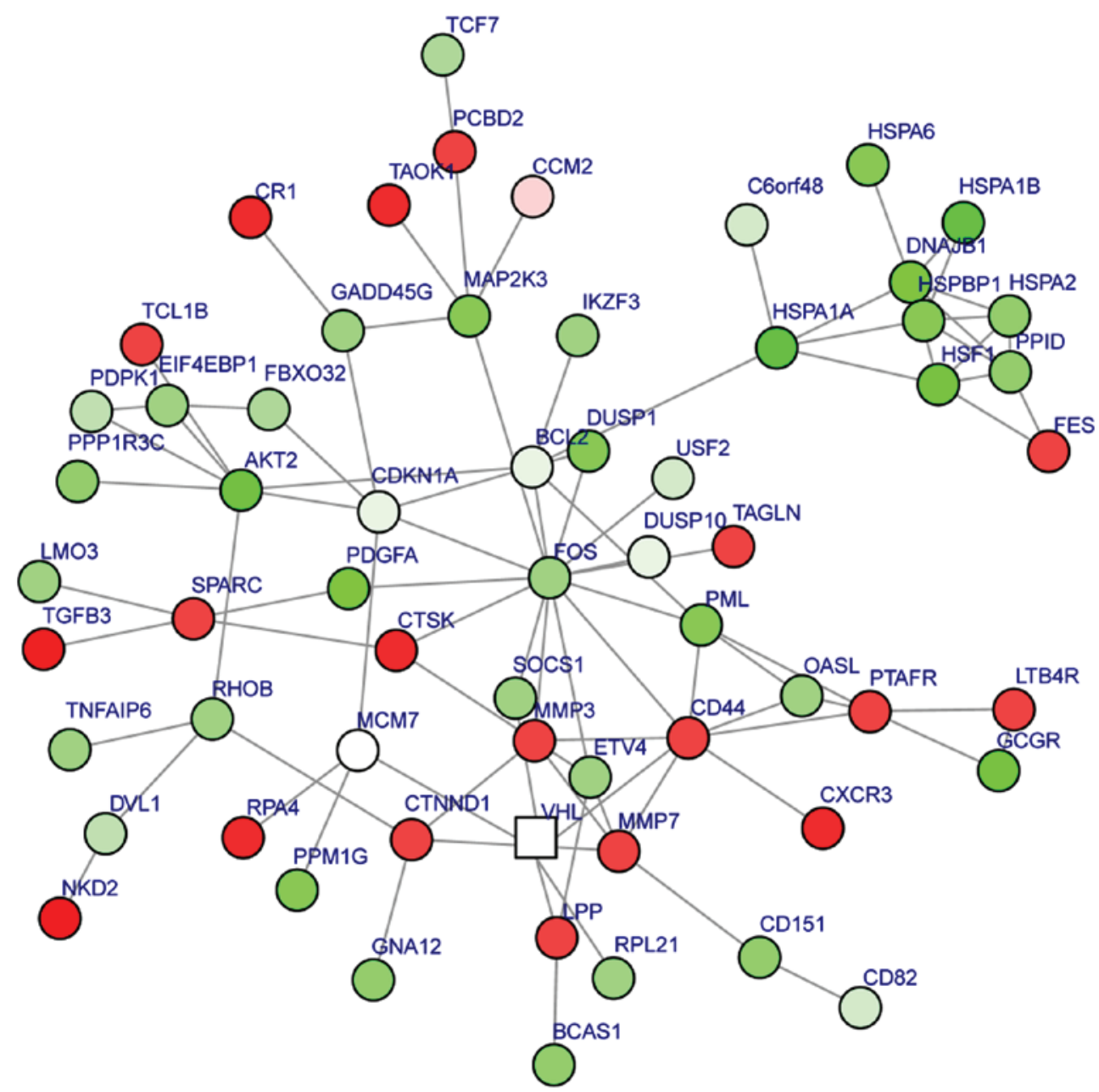

Figure 2. Module obtained from the protein-protein interaction network of the differentially-expressed genes. The shape of the nodes depicts the score: Square indicates a negative score; circle indicates a positive score. A square node with a negative score has a lower importance compared with other nodes. Red circles indicate the upregulated genes and green circles indicate the downregulated genes. The shade of a node has positive association with its llog ${ }_{2}$ fold-changel. 
of retinoblastoma protein in trichostatin A-treated ovarian cancer cells, and therefore p21 may be involved in the cell cycle blockade and the differentiation of the cells (35). These data may indicate that the expression level of CDKN1A exhibits an association with ovarian cancer. In the module in the present study, it was found that CDKN1A could interact with FOS and BCL2, indicating that CDKN1A may also affect ovarian cancer by mediating the two genes.

CD44 is regarded as the main cell surface receptor for hyaluronan (36), an extracellular polysaccharide associated with the progression of ovarian cancer (37). Significant overexpression of CD44 in ovarian cancer cells can induce strong adhesion to the peritoneal mesothelium $(38,39)$, and CD44 has a close association with the implantation of ovarian cancer metastasis (40). The $\mathrm{CD} 44^{+} / \mathrm{CD} 117^{+}$status can be a molecular marker of ovarian cancer-initiating cells (41). As a stem cell marker, CD44 combined with higher aldehyde dehydrogenase 1 family member A1 activity may be used to define ovarian cancer stem cells (42). These data indicate that CD44 may play a role in ovarian cancer. In the module, the present study found that CD44 had interaction associations with FOS, indicating that CD44 may also play a role in ovarian cancer by mediating FOS.

MMPs are a family of zinc-dependent neutral endopeptidases that are overexpressed in the tumor microenvironment and are able to degrade essentially all extracellular matrix components $(43,44)$. Members of the MMP family are involved in tumor cell metastasis and invasion, including the progression of ovarian cancer (45). As the smallest member of the MMP family, MMP7 can be overexpressed in malignant ovarian epithelium and may assist tumor cell invasion by inducing progelatinase activation (46). Meanwhile, MMP7 may act as a marker for detection and as a target for treatment in ovarian cancer (47). These data suggest that MMP7 may have a close association with ovarian cancer. In the module, the present study found there were several interaction associations (e.g., MMP3-MMP7 and MMP7-CD44), indicating that MMP7 may also play a role in ovarian cancer by mediating MMP3 and CD44.

In conclusion, a comprehensive bioinformatics analysis of DEGs that may affect ovarian cancer was conducted in the present study. A total of 284 DEGs were screened, and it was found that BCL2, FOS, CDKN1A, CD44, MMP3 and MMP7 may have a correlation with ovarian cancer. However, further research is required to unravel their roles in ovarian cancer.

\section{References}

1. Scully RE: Pathology of ovarian cancer precursors. J Cell Biochem Suppl 23: 208-218, 1995.

2. Iorio MV and Croce CM: MicroRNA profiling in ovarian cancer. Methods Mol Biol 1049: 187-197, 2013.

3. Yuan ZQ, Sun M,Feldman RI, Wang G, Ma X, Jiang C, Coppola D, Nicosia SV and Cheng JQ: Frequent activation of AKT2 and induction of apoptosis by inhibition of phosphoinositide-3-OH kinase/Akt pathway in human ovarian cancer. Oncogene 19: 2324-2330, 2000.

4. Yin BW and Lloyd KO: Molecular cloning of the CA125 ovarian cancer antigen: Identification as a new mucin, Muc16. J Biol Chem 276: 27371-27375, 2001.

5. Scotton CJ, Wilson JL, Milliken D, Stamp G and Balkwill FR: Epithelial cancer cell migration: A role for chemokine receptors? Cancer Res 61: 4961-4965, 2001.

6. Strieter RM: Chemokines: Not just leukocyte chemoattractants in the promotion of cancer. Nat Immunol 2: 285-286, 2001
7. Scotton CJ, Wilson JL, Scott K, Stamp G, Wilbanks GD, Fricker S, Bridger G and Balkwill FR: Multiple actions of the chemokine CXCL12 on epithelial tumor cells in human ovarian cancer. Cancer Res 62: 5930-5938, 2002.

8. Campbell IG, Russell SE, Choong DY, Montgomery KG, Ciavarella ML, Hooi CS, Cristiano BE, Pearson RB and Phillips WA: Mutation of the PIK3CA gene in ovarian and breast cancer. Cancer Res 64: 7678-7681, 2004.

9. Karakas B, Bachman K and Park B: Mutation of the PIK3CA oncogene in human cancers. Br J Cancer 94: 455-459, 2006.

10. Zhao H, Shen J, Wang D, Guo Y, Gregory S, Medico L, Hu Q, Yan L, Odunsi K, Lele S and Liu S: Associations between gene expression variations and ovarian cancer risk alleles identified from genome wide association studies. PloS One 7: e47962, 2012.

11. Irizarry RA, Hobbs B, Collin F, Beazer-Barclay YD, Antonellis KJ, Scherf U and Speed TP: Exploration, normalization and summaries of high density oligonucleotide array probe level data. Biostatistics 4: 249-264, 2003.

12. Smyth GK: Limma: Linear models for microarray data. In: Bioinformatics and Computational Biology Solutions using R and Bioconductor. Springer, New York, pp397-420, 2005.

13. Zhao M, Sun J and Zhao Z: TSGene: A web resource for tumor suppressor genes. Nucleic Acids Res 41: D970-D976, 2013.

14. Chen JS, Hung WS, Chan HH, Tsai SJ and Sun HS: In silico identification of oncogenic potential of fyn-related kinase in hepatocellular carcinoma. Bioinformatics 29: 420-427, 2013.

15. Palla G, Derényi I, Farkas I and Vicsek T: Uncovering the overlapping community structure of complex networks in nature and society. Nature 435: 814-818, 2005.

16. Lu M, Zhang Q, Deng M, Miao J, Guo Y, Gao W and Cui Q: An analysis of human microRNA and disease associations. PloS One 3: e3420, 2008.

17. Von Mering C, Huynen M, Jaeggi D, Schmidt S, Bork P and Snel B: STRING: A database of predicted functional associations between proteins. Nucleic Acids Res 31: 258-261, 2003.

18. Smoot ME, Ono K, Ruscheinski J, Wang PL and Ideker T: Cytoscape 2.8: New features for data integration and network visualization. Bioinformatics 27: 431-432, 2011.

19. He $X$ and Zhang J: Why do hubs tend to be essential in protein networks? PLoS Genet 2: e88, 2006.

20. Beisser D, Klau GW, Dandekar T, Müller T and Dittrich MT: BioNet: An R-Package for the functional analysis of biological networks. Bioinformatics 26: 1129-1130, 2010.

21. Baekelandt M, Kristensen GB, Nesland JM, Tropé CG and Holm R: Clinical significance of apoptosis-related factors p53, $\mathrm{Mdm} 2$ and Bcl-2 in advanced ovarian cancer. J Clin Oncol 17: 2061, 1999.

22. White E: Life, death and the pursuit of apoptosis. Genes Dev 10: 1-15, 1996.

23. Eliopoulos AG, Kerr DJ, Herod J, Hodgkins L, Krajewski S, Reed JC and Young LS: The control of apoptosis and drug resistance in ovarian cancer: Influence of p53 and Bcl-2. Oncogene 11: 1217-1228, 1995.

24. Miyashita T and Reed JC: Bcl-2 gene transfer increases relative resistance of S49. 1 and WEHI7. 2 lymphoid cells to cell death and DNA fragmentation induced by glucocorticoids and multiple chemotherapeutic drugs. Cancer Res 52: 5407-5411, 1992.

25. Marx D, Binder C, Meden H, Lenthe T, Ziemek T, Hiddemann T, Kuhn W and Schauer A: Differential expression of apoptosis associated genes bax and bcl-2 in ovarian cancer. Anti Cancer Res 17: 2233-2240, 1997.

26. Witham J, Valenti MR, De-Haven-Brandon AK, Vidot S, Eccles SA, Kaye SB and Richardson A: The Bcl-2/Bcl-XL family inhibitor ABT-737 sensitizes ovarian cancer cells to carboplatin. Clin Cancer Res 13: 7191-7198, 2007.

27. Teng CS: Protooncogenes as mediators of apoptosis. Int Rev Cytol 197: 137-202, 2000.

28. Mahner S, Baasch C, Schwarz J, Hein S, Wölber L, Jänicke F and Milde-Langosch K: C-Fos expression is a molecular predictor of progression and survival in epithelial ovarian carcinoma. Br J Cancer 99: 1269-1275, 2008.

29. Le XF, Claret FX, Lammayot A, Tian L, Deshpande D, LaPushin R, Tari AM and Bast RC Jr: The role of cyclin-dependent kinase inhibitor $\mathrm{p} 27 \mathrm{Kip} 1$ in anti-HER2 antibody-induced G1 cell cycle arrest and tumor growth inhibition. J Biol Chem 278: 23441-23450, 2003.

30. Kamb A, Gruis NA, Weaver-Feldhaus J, Liu Q, Harshman K, Tavtigian SV, Stockert E, Day RS III, Johnson BE and Skolnick MH: A cell cycle regulator potentially involved in genesis of many tumor types. Science 264: 436-440, 1994. 
31. Dong Y, Walsh MD, McGuckin MA, Gabrielli BG, Cummings MC, Wright RG, Hurst T, Khoo SK and Parsons PG: Increased expression of cyclin-dependent kinase inhibitor 2 (CDKN2A) gene product P16INK4A in ovarian cancer is associated with progression and unfavourable prognosis. Int J Cancer 74: 57-63, 1997.

32. Gartel AL, Serfas MS and Tyner AL: p21--negative regulator of the cell cycle. Proc Soc Exp Biol Med 213: 138-149, 1996.

33. Wu H, Wade M, Krall L, Grisham J, Xiong Y and Van Dyke T: Targeted in vivo expression of the cyclin-dependent kinase inhibitor p21 halts hepatocyte cell-cycle progression, postnatal liver development and regeneration. Genes Dev 10: 245-260, 1996.

34. Ostrovsky $\mathrm{O}$ and Bengal E: The mitogen-activated protein kinase cascade promotes myoblast cell survival by stabilizing the cyclin-dependent kinase inhibitor, p21WAF1 protein. J Biol Chem 278: 21221-21231, 2003.

35. Strait KA, Dabbas B, Hammond EH, Warnick CT, Ilstrup SJ and Ford CD: Cell cycle blockade and differentiation of ovarian cancer cells by the histone deacetylase inhibitor trichostatin A are associated with changes in $\mathrm{p} 21, \mathrm{Rb}$ and Id proteins. Mol Cancer Ther 1: 1181-1190, 2002.

36. Aruffo A, Stamenkovic I, Melnick M, Underhill CB and Seed B: CD44 is the principal cell surface receptor for hyaluronate. Cell 61: 1303-1313, 1990.

37. Fraser JR, Laurent TC and Laurent UB: Hyaluronan: Its nature, distribution, functions and turnover. J Intern Med 242: 27-33, 1997

38. Cannistra SA, Kansas GS, Niloff J, DeFranzo B, Kim Y and Ottensmeier C: Binding of ovarian cancer cells to peritoneal mesothelium in vitro is partly mediated by CD44H. Cancer Res 53: 3830-3838, 1993.

39. Cannistra SA, Abu-Jawdeh G, Niloff J, Strobel T, Swanson L, Andersen J and Ottensmeier C: CD44 variant expression is a common feature of epithelial ovarian cancer: Lack of association with standard prognostic factors. J Clin Oncol 13: 1912-1921, 1995.
40. Bourguignon LY, Zhu H, Chu A, Iida N, Zhang L and Hung MC: Interaction between the adhesion receptor, CD44 and the oncogene product, p185 HER2, promotes human ovarian tumor cell activation. J Biol Chem 272: 27913-27918, 1997.

41. Zhang S, Balch C, Chan MW, Lai HC, Matei D, Schilder JM, Yan PS, Huang TH and Nephew KP: Identification and characterization of ovarian cancer-initiating cells from primary human tumors. Cancer Res 68: 4311-4320, 2008.

42. Wang YC, Yo YT, Lee HY, Liao YP, Chao TK, Su PH and Lai HC ALDH1-bright epithelial ovarian cancer cells are associated with CD44 expression, drug resistance and poor clinical outcome. Am J Pathol 180: 1159-1169, 2012.

43. Overall CM and López-Otín C: Strategies for MMP inhibition in cancer: Innovations for the post-trial era. Nat Rev Cancer 2. 657-672, 2002

44. Vihinen P and Kähäri VM: Matrix metalloproteinases in cancer: Prognostic markers and therapeutic targets. Int J Cancer 99: 157-166, 2002.

45. Schmalfeldt B, Prechtel D, Härting K, Späthe K, Rutke S, Konik E, Fridman R, Berger U, Schmitt M, Kuhn W and Lengyel E: Increased expression of matrix metalloproteinases (MMP)-2, MMP-9 and the urokinase-type plasminogen activator is associated with progression from benign to advanced ovarian cancer. Clin Cancer Res 7: 2396-2404, 2001.

46. Wang FQ, So J, Reierstad S and Fishman DA: Matrilysin (MMP-7) promotes invasion of ovarian cancer cells by activation of progelatinase. Int J Cancer 114: 19-31, 2005.

47. Tanimoto H, Underwood LJ, Shigemasa K, Parmley TH, Wang Y, Yan Y, Clarke J and O'Brien TJ: The matrix metalloprotease pump-1 (MMP-7, Matrilysin): A candidate marker/target for ovarian cancer detection and treatment. Tumor Biol 20: 88-98, 1999. 